\title{
Autophagy in animal development
}

\author{
Elizabeth A. Allen (10 ${ }^{1} \cdot$ Eric H. Baehrecke ${ }^{1}$
}

Received: 24 October 2019 / Revised: 19 December 2019 / Accepted: 7 January 2020 / Published online: 27 January 2020

(c) The Author(s), under exclusive licence to ADMC Associazione Differenziamento e Morte Cellulare 2020

\begin{abstract}
Macroautophagy (autophagy) delivers intracellular constituents to the lysosome to promote catabolism. During development in multiple organisms, autophagy mediates various cellular processes, including survival during starvation, programmed cell death, phagocytosis, organelle elimination, and miRNA regulation. Our current understanding of autophagy has been enhanced by developmental biology research during the last quarter of a century. Through experiments that focus on animal development, fundamental mechanisms that control autophagy and that contribute to disease were elucidated. Studies in embryos revealed specific autophagy molecules that mediate the removal of paternally derived mitochondria, and identified autophagy components that clear protein aggregates during development. Importantly, defects in mtDNA inheritance, or removal of paternal mtDNA via mitochondrial autophagy, can contribute to mitochondrial-associated disease. In addition, impairment of the clearance of protein aggregates by autophagy underlies neurodegenerative diseases. Experiments in multiple organisms also reveal conserved mechanisms of tissue remodeling that rely on the cooperation between autophagy and apoptosis to clear cell corpses, and defects in autophagy and apoptotic cell clearance can contribute to inflammation and autoimmunity. Here we provide an overview of key developmental processes that are mediated by autophagy in multiple animals.
\end{abstract}

\section{Facts}

- Autophagy proteins are required for multiple functions during embryogenesis.

- Both cell death and cell-corpse clearance rely on autophagy machinery in multiple organisms during developmental tissue remodeling.

- Context-specific requirements exist for core autophagy molecules.

\section{Open questions}

- Do mammals require the autophagic removal of somatic cell protein aggregates during early development?

Edited by F. Pentimalli

Eric H. Baehrecke

eric.baehrecke@umassmed.edu

1 Department of Molecular, Cell, and Cancer Biology, University of Massachusetts Medical School, 423 Lazare Research Building, 364 Plantation St., Worcester, MA 01655, USA
- During context-specific types of autophagy, which core autophagy molecules are required?

- Does autophagy regulate miRNA-mediated gene silencing in mammalian development?

\section{Introduction}

The addition and removal of cells and tissues require transient shifts between anabolism and catabolism during animal development. These processes intersect at the lysosome, an organelle originally regarded as the cell's trash can. Since its discovery in 1955 by Christian de Duve [1], the lysosome has emerged as a cellular signaling center [2-4] that facilitates degradation, homeostasis, and growth. Autophagy delivers cargoes to the lysosome in response to intra- and extracellular cues to facilitate the turnover of cellular components.

Three distinct types of autophagy exist in higher eukaryotes: microautophagy, chaperone-mediated autophagy (CMA), and macroautophagy, which differ both mechanistically and morphologically (Fig. 1a). In 1966, Christian de Duve and Robert Wattiaux coined the term microautophagy [5] to describe a process by which existing endo-lysosomal membranes protrude or invaginate to sequester cargoes. Microautophagy has been most studied in yeast, and is either 


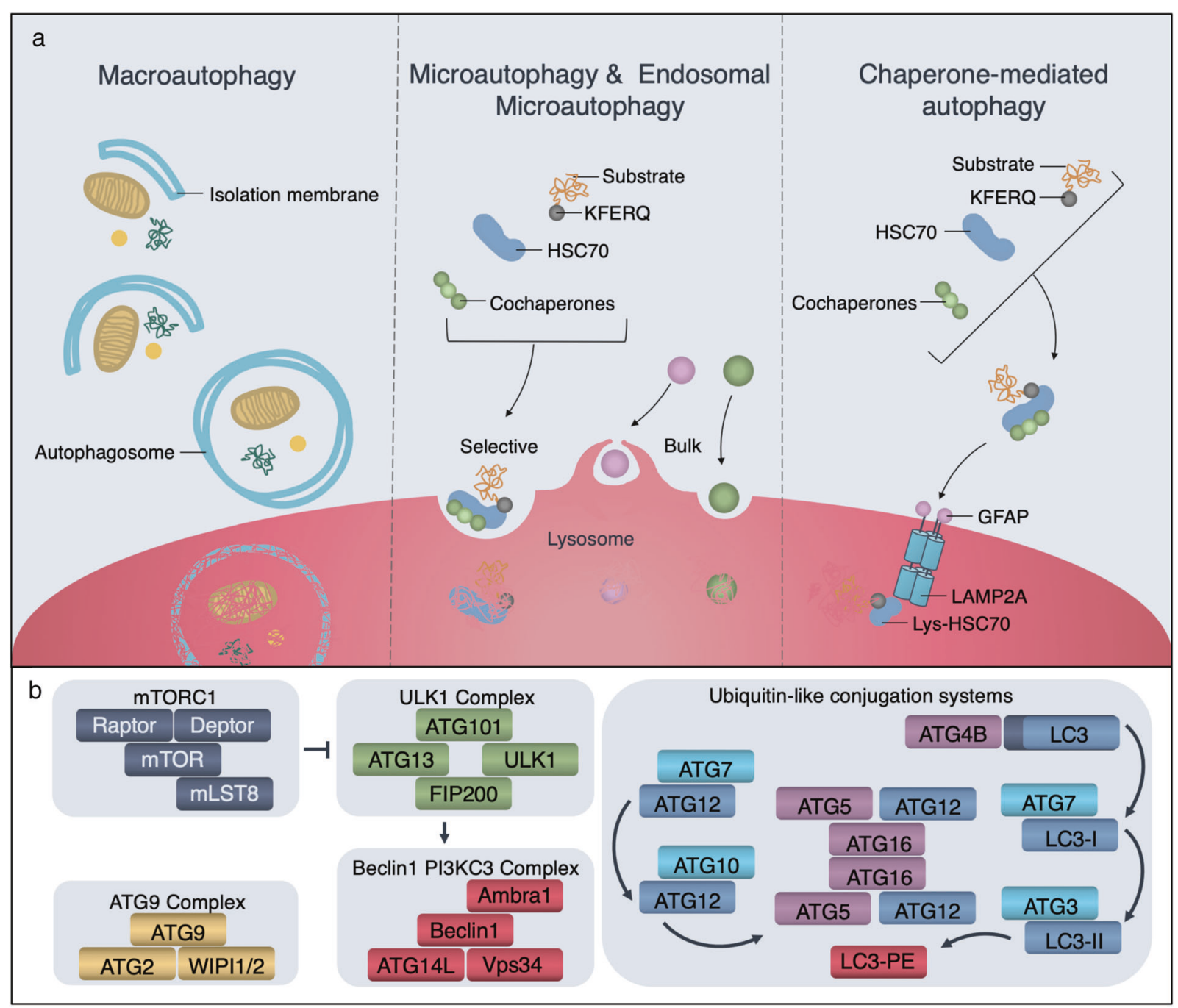

Fig. 1 Autophagic pathways and components. a Autophagic pathways converge at the lysosome where cargoes are degraded by lysosomal enzymes. In macroautophagy, a double-membrane isolation membrane elongates, expands, and seals to make an autophagosome around cytoplasmic components before fusing with the lysosome. Microautophagy and endosomal microautophagy deliver small cargoes directly to the lysosome either without or with chaperones, respectively. Chaperone-mediated autophagy requires the lysosomeassociated membrane protein 2A (LAMP2A), in addition to molecular chaperones. b Conserved autophagic components regulate macroautophagy in development. Please refer to the text for further descriptions. selective, which degrades specific cellular components, or non-selective, which targets random cytosolic components. Microautophagy in higher organisms remains elusive, and is better understood in the context of endosomal microautophagy (e-MI), in which late endosomal membranes generate invaginating vesicles that internalize ubiquitinated membrane proteins [6]. Similarly, single proteins can be degraded by CMA, which delivers target proteins to the lysosome via a molecular chaperone. In this case, heat shock protein family A (Hsp70) member 8 (HSPA8) recognizes substrate proteins with a KFERQ-motif [7], and delivers them to lysosomal-associated membrane protein 2A (LAMP2A) [8] for unfolding, translocation across the lysosomal membrane, and subsequent degradation $[9,10]$.
Macroautophagy (hereafter autophagy) requires the biogenesis of specialized membranes that sequester cytoplasmic cargoes, including mitochondria, for delivery to the lysosome. In their foundational report in 1962, Ashford and Porter and in many cases, lysosomes contained mitochondria [11], which demonstrated both hormone- and starvationinduced autophagy for the first time. Shortly thereafter, Arstila and Trump provided evidence that autophagy exists as a sequential process that begins with the formation of a double-membraned autophagosome, which is free of hydrolytic enzymes, and this structure is later observed as a single-membrane autolysosome, often containing partially degraded organelles and lysosomal enzymes [12]. Later studies in the yeast Saccharomyces cerevisiae revealed the 
Table 1 Autophagy gene orthologs across organisms.

\begin{tabular}{|c|c|c|c|}
\hline S. cerevisiae & $\begin{array}{l}\text { C. } \\
\text { elegans }\end{array}$ & D. melanogaster & H. sapiens \\
\hline$A T G 1$ & $u n c-51$ & Atg1 & $U L K 1, U L K 2$ \\
\hline ATG13 & epg-1 & Atg13 & KIAA0652 \\
\hline \multirow[t]{3}{*}{ ATG17 } & & Atg17 & $F I P 200, R B 1 C C 1$ \\
\hline & epg-7 & & \\
\hline & epg-9 & Atg 101 & ATG101 \\
\hline VPS30/ATG6 & bec- -1 & Atg6 & BECN1 \\
\hline VPS34 & vps-34 & Vps34/Pi3K59F & VPS34/PIK3C3 \\
\hline VPS15 & vps-15 & Vps15/ird1 & VPS15/PIK3R4 \\
\hline \multirow[t]{5}{*}{ ATG14 } & epg-8 & $\operatorname{Atg} 14$ & ATG14/barkor \\
\hline & & CG6116 & UVRAG \\
\hline & & endoB & $S H 3 G L B 1$ \\
\hline & & buffy & $B C L 2$ \\
\hline & & & $A M B R A 1$ \\
\hline ATG3 & atg-3 & Atg3 & ATG3 \\
\hline ATG4 & $\begin{array}{l}\text { atg-4.1, } \\
\text { atg-4.2 }\end{array}$ & Atg 4 & $\begin{array}{l}A T G 4 A, A T G 4 B, \\
A T G 4 C, A T G 4 D\end{array}$ \\
\hline ATG5 & atg-5 & $\operatorname{Atg} 5$ & ATG5 \\
\hline$A T G 7$ & $\operatorname{atg}-7$ & $\operatorname{Atg} 7$ & $A T G 7$ \\
\hline$A T G 8$ & $\begin{array}{l}\operatorname{lgg}-1 \\
\operatorname{lgg}-2\end{array}$ & $\operatorname{Atg} 8 a, \operatorname{Atg} 8 b$ & $\begin{array}{l}\text { MAP1LC } 3 A, \\
M A P 1 L C 3 B, \\
\text { MAP1LC } 3 C, \\
\text { GABARAP, } \\
\text { GABARAPL2 }\end{array}$ \\
\hline ATG10 & atg-10 & Atg10 & ATG10 \\
\hline ATG12 & $\operatorname{lgg}-3$ & $\operatorname{Atg} 12$ & ATG12 \\
\hline ATG16 & $\begin{array}{l}\text { atg-16.1, } \\
\text { atg-16.2 }\end{array}$ & Atg16 & $A T G 16 L 1, A T G 16 L 2$ \\
\hline \multirow[t]{6}{*}{ ATG18 } & atg-18 & Atg18a, Atg18b & WIPII, WIPI2 \\
\hline & epg-2 & & \\
\hline & epg-3 & Tango5 & $V M P 1$ \\
\hline & epg-4 & tank & $E I 24$ \\
\hline & epg-5 & Epg5 & EPG5 \\
\hline & epg-6 & & WIPI3, WIPI4 \\
\hline ATG2 & $\operatorname{atg}-2$ & $\operatorname{Atg} 2$ & ATG2 \\
\hline \multirow[t]{5}{*}{$A T G 9$} & atg-9 & $\operatorname{Atg} 9$ & ATG9A, $A T G 9 B$ \\
\hline & pgl-3 & & \\
\hline & $r a b-7$ & $R a b 7$ & $R A B 7$ \\
\hline & sepa-1 & & \\
\hline & sqst-1 & $r e f(2) p$ & SQSTM1/p62 \\
\hline LST8 & $m l s t-8$ & Lst8 & $M L S T 8$ \\
\hline$T E P 1$ & daf-18 & Pten & PTEN \\
\hline TOR1, TOR2 & let-363 & Tor & TOR \\
\hline KOG1 & daf-15 & raptor & Raptor \\
\hline RHB1 & rheb-1 & Rheb & Rheb \\
\hline TSC11 & rict-1 & rictor & Rictor \\
\hline
\end{tabular}

core autophagy machinery that is encoded by over $30 \mathrm{ATG}$ (autophagy-related) genes [13-16], most of which are conserved in higher animals $[17,18]$ (Table 1).
Autophagy membrane dynamics are characterized by sequential formation of morphologically distinct autophagic structures (Fig. 1b). Following autophagy initiation, an isolation membrane forms and expands around cargoes to eventually seal and form a double-membrane autophagosome. The autophagosome fuses with the lysosome to generate an autolysosome. Following degradation, autophagy commences with autolysosome reformation via the tubulation and scission of proto-lysosomes that mature and later contribute to the lysosomal pool.

Specific ATGs and their regulators control different stages of autophagy, and the intricacies of their molecular regulation are extensively described elsewhere [17, 19]. Briefly, autophagosome formation requires the unc-51-like kinase (ULK/Atg1) complex, the class III phosphatidylinositol 3-kinase (PtdIns3K)/Vps34 complex I (PI3KC3), two ubiquitin-like protein (Atg12 and Atg8/LC3) conjugation systems, and the transmembrane proteins ATG9/Atg9 and VMP1 [20-22]. The protein kinase mechanistic target of rapamycin complex 1 (mTORC1/TORC1), which includes mTOR, regulatory-associated protein of mTOR (Raptor), mammalian lethal with $\mathrm{Sec} 13$ protein 8 (mLst8/ Lst8), proline-rich AKT substrate $40 \mathrm{kDa}$ (PRAS40), and DEP-domain-containing mTOR-interacting protein (Deptor), functions upstream of autophagy [23]. mTORC1 is typically activated at the lysosome by both growth factors and nutrients, and promotes the activity of translationregulating factors, such as the eukaryotic initiation factor $4 \mathrm{E}$ binding protein and the ribosomal protein S6 kinase. Meanwhile, mTORC1 represses autophagy via ULKcomplex phosphorylation [23]. When nutrient levels drop, mTORC1 repression occurs, and autophagy proceeds with the activation of the ULK complex, PI3KC3-mediated generation of $\mathrm{PI}(3) \mathrm{P}$ at early autophagosomal membranes, the ATG12 complex, and the conjugation of ATG8 family proteins to the membrane lipid phosphatidylethanolamine (PE) [22, 23]. Following closure, autophagosomes undergo a maturation process that includes PI(3)P turnover and removal of ATG8 proteins by members of the ATG4 protease family, as well as recruitment of fusion machinery, which includes RAB7, the homotypic vacuole fusion and protein sorting (HOPS) tethering complex, SNARES, and others [24]. Upon lysosome fusion, the inner membrane of the autophagosome and its contents are degraded by lysosomal enzymes, and amino acids and sugars are effluxed out of the lysosome via specific transporters, including the sugar efflux Spinster (SPNS), which is required for degradation, autolysosome reformation, and reactivation of mTORC1 [25, 26].

Here we summarize how autophagy functions in animal development, including fertilization, embryogenesis, organogenesis, neural development, invertebrate metamorphosis, and during regeneration. 
Autophagy in embryogenesis-from fertilization to birth

Autophagy occurs following conception and throughout embryogenesis in various animals. In addition to providing a survival mechanism when nutrients are scarce, autophagy eliminates organelles and protein aggregates at specific time points during development. Importantly, several autophagy genes are required for survival beyond specific developmental stages.

\section{Elimination of paternal mitochondria post-fertilization}

Despite the fact that paternal mitochondria enter the oocyte upon fertilization, eukaryotes inherit only maternal mitochondrial DNA (mtDNA). Paternal mitochondria require removal from the ooplasm to prevent heteroplasmy, the presence of more than one type of organellar genome, and this process is mediated by mitochondrial autophagy (mitophagy) across diverse taxa, including C. elegans [27]. Hermaphrodite worms with homozygous mutations in lgg-1 (mammalian LC3) can develop to adults and produce self-fertilized eggs. However, many eggs fail to hatch, and of those that do, a large percentage fail to survive beyond the first larval stage [28]. Upon fertilization, paternal mitochondria and their genomes, along with membranous organelles, are rapidly degraded within the oocyte by LGG1/2 (LC3)-dependent autophagy $[28,29]$ that is mediated by maternal autophagy proteins [28] (Fig. 2a). However, major sperm proteins, which are required for $C$. elegans sperm motility and enter the oocyte at the same time, are not degraded by autophagy, which suggests that this is a type of selective autophagy [29]. Nematode sperm features a unique organelle called the membranous organelle, which functions first in early spermatogenesis as transport vesicles for sperm-specific components and later in the crawling spermatozoa delivering components to the plasma membrane via fusion [30]. Interestingly, membranous organelles, but not mitochondria, are ubiquitinated during post-fertilization autophagy, and ubiquitination precedes LGG-1/2 recruitment [28, 29]. In the mouse oocyte, post-fertilization paternal mitochondria stain positive for antibodies against LC3, GABARAP, and p62 [29]. The clearance of paternal mitochondria appears to be a ubiquitin-dependent process in mice because mitochondria could also be stained with Ubi-K63 antibodies [29]. Interestingly, upon proteasomemeditated mitochondrial rupture and mitochondrial depolarization, the inner mitochondrial protein Prohibitin 2 (PHB2) directly binds with lipidated LC3 to mediate mitophagy in mammals [31] (Fig. 2a). Similarly, PHB2 is required for post-fertilization paternal-mitochondrial clearance in C. elegans [31]. Together these findings provide evidence that autophagy plays an important role in maternal mtDNA inheritance.

\section{Protein aggregate elimination during $C$. elegans embryogenesis}

Protein aggregate clearance is critical to cellular health, and the discovery of mechanisms that promote protein aggregate removal may lead to therapies for degenerative diseases, such as Parkinson. Early development in worms is an ideal system in which to study the biology of protein aggregate formation and removal.

During early $C$. elegans embryogenesis, protein aggregates are degraded by autophagy (Fig. 2b). Maternally loaded $\mathrm{P}$ granules are a specialized type of proteinRNA aggregate. $P$ granules disperse throughout the cytoplasm of new embryos and eventually localize to specific germline cell blastomeres via asymmetric cell divisions [32]. Somatic cells also acquire $\mathrm{P}$ granule components during these early cell divisions. However, these somatic $\mathrm{P}$ granules lack some components found transiently in germline blastomeres [33]. Somatic cells use autophagy to selectively eliminate several $\mathrm{P}$ granule components, such as PGL-1 and PGL-3. In developing wild-type animals, autophagic structures surround PGL-1labeled protein aggregates [33]. However, autophagy mutant worms gradually accumulate $\mathrm{P}$ granules to form what is referred to as PGL granules that contain PGL-1 protein aggregates [33]. This selective autophagy in somatic cells is mediated by zygotically derived SEPA-1, an autophagy adapter molecule that directly interacts with both PGL-3 and LGG-1 (LC3), an interaction reminiscent of mammalian p62 and Drosophila ref(2)p, which interact with polyubiquitinated protein aggregates to mediate autophagy [34, 35]. A genetic screen to uncover additional regulators of autophagy in worms revealed that the nematode-specific protein EPG-2, which can form aggregates on its own and is degraded by autophagy, plays a specific role in P-granule component degradation, possibly as a receptor that directs $\mathrm{P}$ granules to autophagy components [36]. Interestingly, recent work indicates that PGL clearance by autophagy depends on liquid phase separation, and that this is regulated by mTORC1 as an adaptation to stress during embryonic development [37]. It remains to be determined if similar requirements exist in higher eukaryotes for the autophagic removal of somatic cell protein aggregates during early development.

\section{Autophagy in the mouse oocyte to embryo transition}

In mammals, pre-implantation embryos lack placental nutrients. Thus, the building blocks that are required to generate the newly formed zygotic genome are thought to 


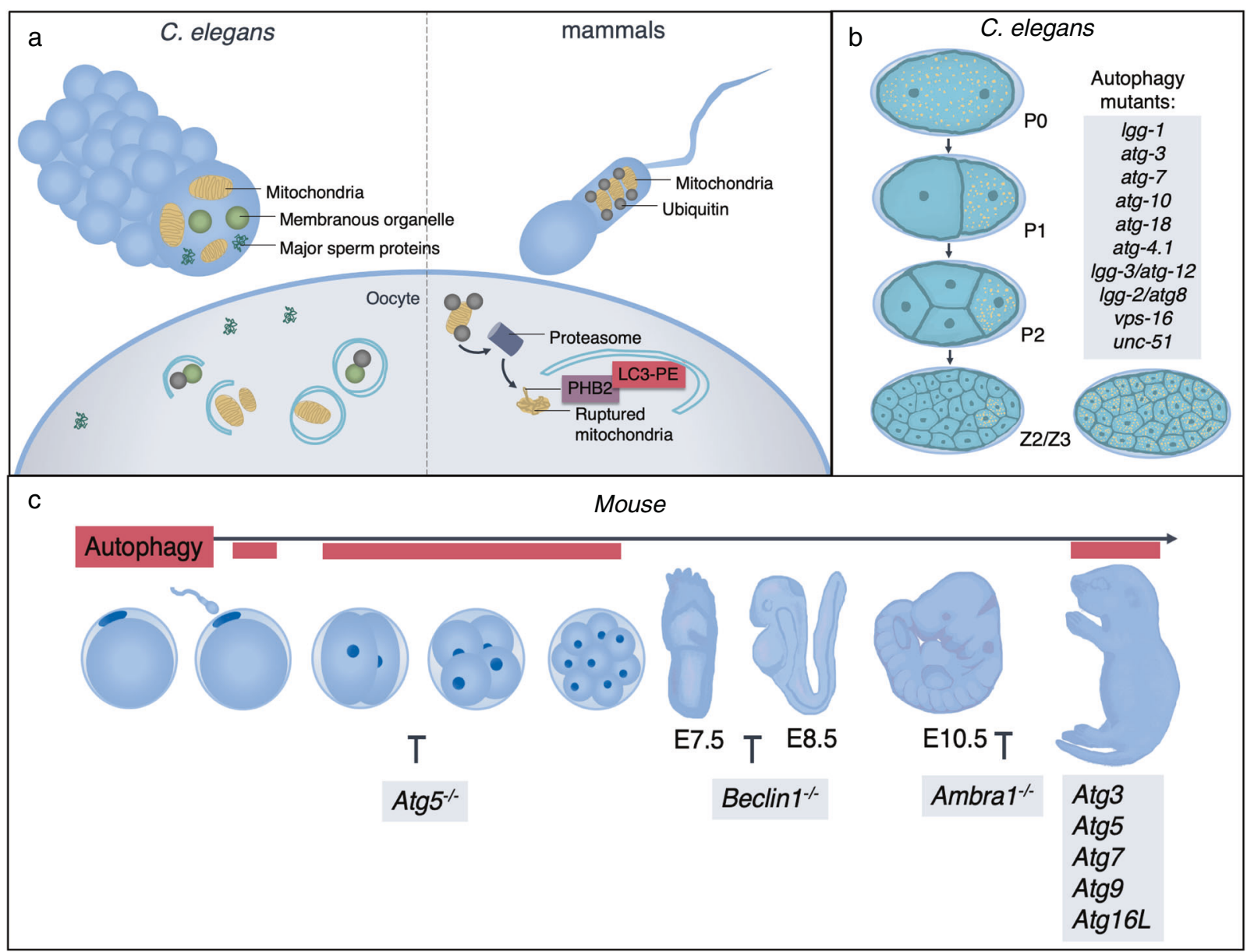

Fig. 2 Autophagy in embryogenesis. Selective autophagy mediates (a) paternal-mitochondria removal following fertilization in C. elegans and mammals and (b) protein aggregate clearance in C. elegans requires core autophagy components (gray box). c Autophagy occurs

be initially harvested post-fertilization from oocyte-derived maternal proteins. Indeed, autophagy induction occurs within 2-4h after fertilization of the mouse oocyte [38], which coincides with rapid degradation of proteins [39] (Fig. 2c). For reasons we don't fully understand, autophagy is undetectable late in the 1-cell stage through the early 2-cell stage. At the middle of the 2-cell stage, autophagy is reactivated, and high autophagic activity continues through the 4- to 8-cell stage. Although autophagy is required for neonate survival, post-fertilization autophagy is not required for normal embryonic development [40, 41]. Thus, it is thought that maternally-derived proteins existing in the oocyte after fertilization might facilitate autophagy. Interestingly, oocyte-specific Atg5 knockout mice fertilized with Atg5-null sperm are embryonic lethal, and development arrests at the 4-cell to 8-cell stage. Oocyte-specific Atg5 knockout mice produce pups only when fertilized with wild-type sperm but not with Atg5 mutant sperm [38]. Although we lack a complete understanding for the cause of lethality at the 4- to 8-cell stage in autophagy-deficient in waves (red bars) across early mouse embryogenesis and is required for neonate survival. Mutations in core autophagy genes (gray) result in lethality at different developmental time points.

embryos, protein synthesis is significantly decreased, which suggests that amino acids are contributed by autophagy during this stage [38].

Oocytes possess active mTORC1 [38] prior to fertilization, and immediately after fertilization, mTORC1 is inactivated. However, despite an inverse correlation between mTORC1 activity and autophagy in fertilized oocytes, autophagy regulation is mTORC1-independent [42]. In support of this, mTORC1 suppression with the inhibitor Torin1 decreases mTORC1 activity in unfertilized oocytes but fails to induce autophagy in oocytes and early embryos. In addition, mTORC1 activation in one-cell embryos following cycloheximide treatment fails to suppress autophagy. Post-fertilization autophagy is, however, PI3Kdependent because treating embryos with the PI3K inhibitor wortmannin suppresses autophagy. To our knowledge, it remains unknown if the ULK complex is required for this temporal wave of post-fertilization autophagy. Indeed, ULK-independent autophagy programs exist in multiple contexts [43-45]. 


\section{Autophagy in mouse embryogenesis}

Beclin1 plays an essential role in early mouse embryogenesis [46]. Homozygous mutations in Beclinl result in early embryonic lethality between days E7.5 and E8.5, and severe developmental delays exist in animals at day E7.5. In addition to being extremely small, null Beclinl mutant embryos possess defects in pro-amniotic canal closure and amniotic fold development, and cell death is apparent throughout.

Ambra1 is a large protein with an amino terminal WD40 domain that positively regulates autophagy in a Beclin1dependent manner in vertebrates. Experiments using Ambral gene-trap mutant mice demonstrate that Ambra1 is necessary to control cell proliferation and promotes cell survival during nervous system development [47]. High Ambral expression exists throughout the neuroepithelium of day E8.5 mouse embryos, and at day E11.5, expression occurs in the ventral spinal cord, encephalic vesicles, neural retina, limbs, and dorsal root ganglia. Homozygous mutations in Ambral result in embryonic lethality and neural tube defects between E10 and E14.5, with neuroepithelium hypertrophy and accumulation of ubiquitinated proteins, enlarged spinal cord, and excessive apoptosis in specific regions of the nervous system. Although Ambra1 functions with Beclin1, Ambral mutants survive longer than Beclin1 mutants. This difference may be due to a tissue-specific function of Ambral because it is highly expressed in the nervous system. Indeed, Ambral also functions with Beclin1 in adult neurogenesis to sustain a neural stem cell pool [48] and mutations in Ambral are associated with several neurological pathologies [49]. However, in addition to its role in autophagy, Beclin1 functions in an endocytosis regulatory complex. Thus, early Beclinl lethality could also be explained by potential defects in developmental endocytosis.

\section{Autophagy and apoptotic corpse clearance in development}

During development, autophagy and apoptosis work together to eliminate massive numbers of cells. Autophagy has been associated with dying cells during development of diverse taxa. During apoptosis, dying cells are quickly engulfed by phagocytosis, an internalization process by which extracellular constituents are sequestered and processed within a single-membrane phagosome that is eventually degraded by the lysosome. Efficient apoptotic corpse removal requires that apoptotic cells generate cell-surface "eat-me" signals and secrete "come-get-me" signals, and also, that phagocytic cells migrate to cell death sites, recognize, and take-up the dying cells [50] (Fig. 3). Several lines of evidence support a role for autophagic components

\section{Apoptotic Cell Phagocyte}

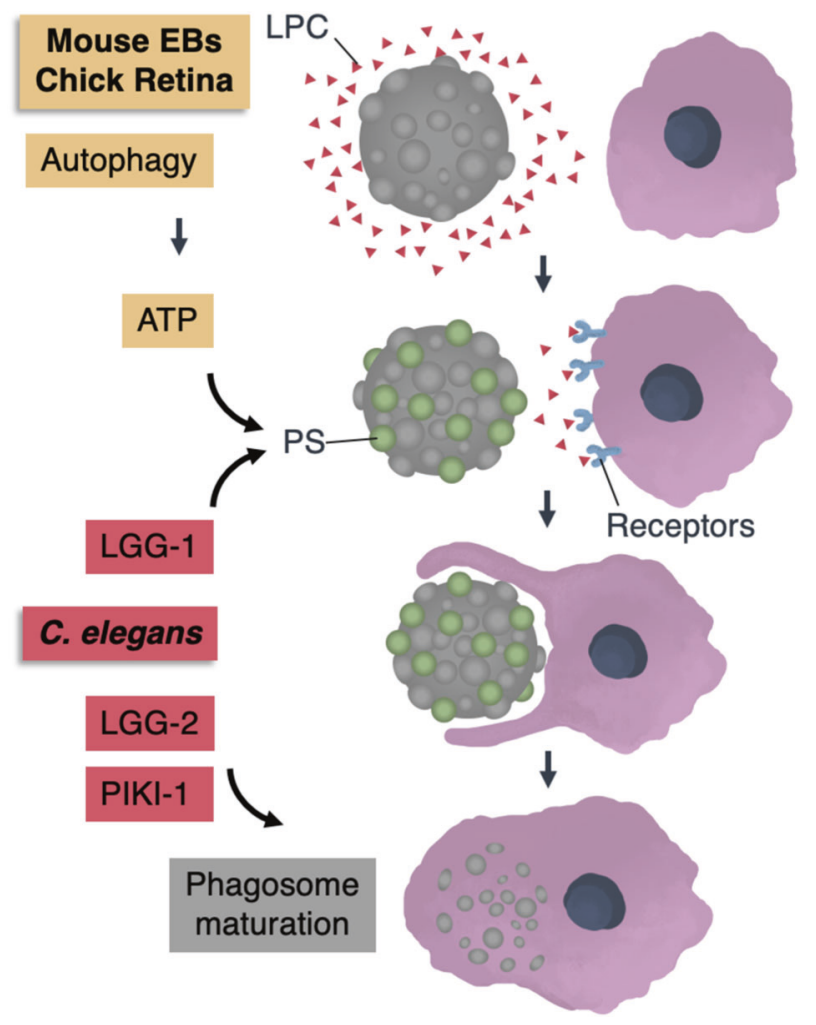

Fig. 3 Apoptotic corpse cell clearance. Dying cells release "find me" signals, such as lysophosphatidylcholine (LPC), which are recognized by phagocytic cells. Dying cells expose cell-surface phosphatidylserine (PS) in a context-specific manner (refer to text for details). Phagocyte receptors recognize PS, engulf and internalize corpse cells, and phagosomes mature along a lysosome-destined pathway that requires some autophagy components.

within both apoptotic and phagocytic cells during developmental programmed cell death.

\section{Autophagic corpse clearance in C. elegans}

Much of our understanding of cell death pathways stems from experiments in C. elegans. Like in mammals, autophagy cooperates with apoptosis to facilitate corpse clearance in worms. However, unlike flies and mammals, C. elegans lack professional phagocytes, and instead, apoptotic cells rely on neighboring cells for engulfment.

During C. elegans embryogenesis, 113 cells undergo programmed cell death [51] followed by corpse clearance. Worm embryos with mutations in genes that regulate multiple steps in autophagy contain more cell corpses than controls [52, 53], while corpse clearance does not require specialized autophagy cargo adapter or receptor molecules that mediate clearance of protein aggregates or $\mathrm{P}$ granules [53]. Autophagy genes are not required for corpse engulfment but instead cooperate with the class II PI3 kinase 
PIKI-1 to promote PI(3)P-dependent phagosome maturation [53]. Differential roles exist for LGG-1/GABARAP and LGG-2/LC3 in apoptotic corpse clearance in C. elegans embryos [54]. Apoptotic cells and phagosomes are both enriched with LGG-1 and LGG-2. However, LGG-1 promotes apoptotic-cell phosphatidylserine (PS) exposure, while LGG-2 mediates phagosome-lysosome interactions. Unlike mouse embryoid bodies (EBs) and chick retina (discussed below), autophagy gene mutations fail to impair PS exposure in C. elegans embryonic cell corpses [52].

During the first larval stage, $C$. elegans $\mathrm{Q}$ neuroblasts divide asymmetrically, and their smaller daughter cells undergo apoptotic death. In the phagocyte, sequential function of autophagy proteins ATG-18 and EPG-5 promotes phagosome maturation and enables corpse degradation but not removal [55]. This process is, however, UNC51- and ATG-7-independent because unc-51 and atg-7 mutant worms lack Q-cell corpse-clearance defects [55]. Further, adult $C$. elegans hermaphrodites undergo a germ cell death in which surrounding gonadal sheath cells phagocytose germ cell corpses. Here, corpse degradation requires BEC-1, ATG-18, and UNC-51 [56]. Both bec-1 mRNA and BEC-1::GFP are detectable throughout development, with highest bec-1 mRNA expression during embryogenesis [57] and BEC-1::GFP in differentiating organs. Interestingly, loss of both maternal and zygotic bec1 results in early embryonic lethality, but animals with maternally-derived wild-type BEC-1 live to early adulthood despite motility defects and vacuole accumulation in various tissues [56, 57]. However, it remains difficult to determine the exact role for BEC-1 in development because, in addition to impaired autophagy, bec-1 mutants display endocytosis and retrograde transport defects [56], and evidence indicates that BEC-1/Beclin 1 exists in at least two complexes, an autophagy- and an endocytosis-specific complex.

\section{Corpse clearance in Drosophila embryogenesis}

During the final stages of Drosophila embryogenesis, an extra-embryonic tissue called the amnioserosa is eliminated by programmed cell death that involves both autophagy and caspases. At dorsal closure, $\sim 90 \%$ of amnioserosa cells internalize and degenerate, while basal extrusion followed by anoikis accounts for cell death in the remaining $10 \%$ of amnioserosa cells [58], and phagocytic macrophages engulf the dying amnioserosa cells [59]. In caspase-deficient embryos, amnioserosa tissue persists several hours beyond when control embryo amnioserosa degenerates [59]. However, autophagic activity increases in late dorsal closure stage embryos prior to amnioserosa cell death in both wildtype and caspase-deficient embryos [59]. Autophagy suppression by activated growth signaling delays amnioserosa degeneration, and autophagy activation by Atgl misexpression promoted early amnioserosa dissociation and cell death, which could be suppressed by caspase inhibition [59]. Similarly, autophagy promotes, but is not required for amnioserosa basal cell extrusion during dorsal closure stage [60]. Thus, developmental autophagy precedes caspasedependent amnioserosa cell death, which suggests that autophagy could mediate caspase activation in specific contexts.

\section{Autophagy-dependent corpse clearance during vertebrate embryogenesis}

In rodents, developmental programmed cell death occurs early in embryogenesis with cavitation that commences just prior to gastrulation. The solid mass of ectoderm cells undergoes programmed cell death to form the pro-amniotic cavity [61]. An in vitro model of this process utilizes mouse embryonic stem cells, which form undifferentiated cell aggregates and develop into simple EBs. Simple EBs contain an outer layer of endodermal cells and an inner solid mass of ectodermal cells that undergo programmed cell death to form cystic EBs.

Using EBs, it was discovered that atg5 and beclin1 are required for the removal of dead cells by phagocytic cells during cavitation [62]. A ubiquitous dying-cell eat-me signal, PS, translocates from the inner to the outer leaflet of the plasma membrane lipid bilayer early during apoptosis. In addition, dying cells secrete lysophosphatidylcholine (LPC), a potent chemoattractant signal recognized by professional phagocytes, including macrophages. Both PS exposure and LPC secretion are essential for apoptotic cell engulfment [50]. In autophagy gene-deficient EBs, corpse clearance, and cavitation fail because dying cells lack outerleaflet PS, secrete lower levels of LPC compared with wildtype EBs, and have reduced ATP levels [62]. The defects in PS exposure, LPC secretion, and ATP levels are reversible after treating EBs with methylpyruvate, a cell-permeable tricarboxylic acid cycle substrate, which also restores corpse clearance and cavitation.

A similar role for autophagy in corpse clearance exists in chick retinal development. The embryonic chick retina is a well-characterized model in which the processes of neural development and cell death coexist. Retinal neuroepithelium proliferates, generating the retinal ganglion cells, which are the first neurons, and simultaneously, cell death occurs centrally. Autophagy is active in the E4 chick retina, in the E5 neuroepithelium and retinal ganglion cells, and in all layers of the E9 retina. At each of these stages, autophagy can be inhibited by exposure to 3-methyladenine (3MA) [63, 64]. Autophagy inhibition by 3-MA in E4 organotypic neuroretinal cultures results in apoptotic cell body accumulation with cells that fail to expose PE and harbor 
reduced ATP levels, and methylpyruvate treatment rescues these defects [63]. However, 3-MA treatment produces differential spatiotemporal effects. In E5 retinas, 3-MA impairs dorsotemporal area cell-corpse clearance. Meanwhile 3-MA has no effect on the clearance of dying cells at the optic nerve and optic fissure area, and E9 retinal ganglion cell programmed cell death remains unaffected by 3-MA. Interestingly, mouse $\operatorname{Atg} 5^{-1-}$ embryos feature a defect in apoptotic-corpse engulfment in retina and lungs [62]. Taken together, these studies provide evidence that autophagy-dependent ATP production promotes PSmediated apoptotic cell clearance in some developmental programmed cell death contexts, but not all.

\section{Autophagy in post-embryonic animal development}

Autophagy participates in post-embryonic animal development where it can mediate gene silencing, cell-fate determination and promote survival in stressful environments. In fact, multiple animals require autophagy either to survive periods of developmental nutrient restriction or to facilitate developmental cell death during tissue remodeling.

\section{Autophagy in C. elegans development during stress}

C. elegans normally develop through four continuous larval stages. However, when environmental conditions are insufficient to support successful reproduction, such as either limited food supply, high population density or increased temperature, $C$. elegans enter a specialized and reversible developmental stage called the dauer diapause to survive (Fig. 4a). In this case, developmental arrest occurs at the second molt, and instead of proceeding to a typical third larval stage, animals cease feeding, increase lipid storage, and become thin and dense, mainly as result of hypodermal shrinkage. Autophagy increases during dauer stage, and the remodeling that occurs during dauer formation requires bec-1, atg-1, atg-7, atg-8, and atg-18 [65].

\section{Autophagy in miRNA-mediated gene silencing and cell fate specification}

MicroRNAs (miRNAs) repress gene expression through posttranslational complementary interactions with a target mRNA at its $3^{\prime}$ untranslated region. miRNAs cooperate with the effector proteins, Argonaute and the GW182 family member, to form miRNA-induced silencing complexes (miRISC) and silence genes by either perfectly or imperfectly complementing the mRNA to facilitate target mRNA degradation or translation inhibition, respectively $[66,67]$.

During development, C. elegans miRNAs control developmental cell-lineage timing and regulate heterochronic genes, which encode temporally expressed components that facilitate precise developmental transitions [68]. An ortholog of hunchback $(\mathrm{hb})$ in Drosophila, which controls pattern formation in the early embryo [69, 70], hbl-1 encodes a $\mathrm{C} 2 \mathrm{H} 2$-type zinc finger transcription factor that is expressed spatio-temporally during worm embryogenesis [71]. The developmental switch from L2 to L3 is controlled by $h b l-1$ mRNA inhibition via the let-7 miRNA family members, mir-84, mir-48, and mir-241 [68, 72]. Later the switch from L4 to adult requires that let-7 miRNA targets lin-41 mRNA [68]. Thus, mutations in let-7 miRNA family members [68], or in GW182 proteins [73, 74], result in worms with heterochronic phenotypes that present as developmental delays, dysregulated body morphologies, or differentiation defects. However, autophagy gene mutations suppress the heterochronic defects caused by mutations in the miRISC components, dcr-1, alg-1, and ain-1 [75] (Fig. 4a). In autophagy mutant animals that express GFP-labeled target mRNAs, GFP signal is reduced; indeed, AIN-1 colocalizes with SQST-1/p62 in autophagy mutants and is selectively degraded by autophagy [75]. When autophagy is activated by starvation or TOR inhibition in autophagy-proficient worms that express GFP-labeled target mRNAs, the GFP signal is enhanced [75]. Thus, in C. elegans, autophagy degrades a miRISC component and regulates miRNAmediated gene silencing during development. A similar role for autophagy in miRNA regulation exists in HeLa cells where autophagy selectively degrades DICER and AGO2 via the selective autophagy adapter NDP52 [76]. However, many studies focus on how miRNAs regulate autophagy [77], and we have only started to investigate how autophagy regulates miRNA-mediated gene expression.

Autophagy regulation by miRNAs exists in adult rodent neurogenesis. Neurogenesis occurs in the adult rodent brain via neural stem cells, which reside in the anterior subventricular zone and continuously give rise to neuroblasts. Neuroblasts migrate along the rostral migratory stream before arriving at the olfactory bulb where they migrate radially, differentiate, and integrate as interneurons into preexisting neural circuits. In the adult rodent brain, the let-7 family is highly expressed in newborn neurons of the olfactory bulb, where it promotes radial migration, neuron maturation, and autophagy [78]. Neurite length and branch point numbers are reduced when let-7 is depleted. Furthermore, electron micrographs of newborn let-7 knockdown neurons display cells with fewer and smaller autophagic structures compared with control neurons, and p62 accumulates while LC3 levels are reduced in let-7 depleted neurons compared with controls. Importantly, in let-7 knockdown cells, misexpression of either Becn1 or the transcription factor EB (TFEB), which is a transcription factor that regulates autophagy gene expression, partially rescues the let-7 neuron-knockdown phenotypes, including 


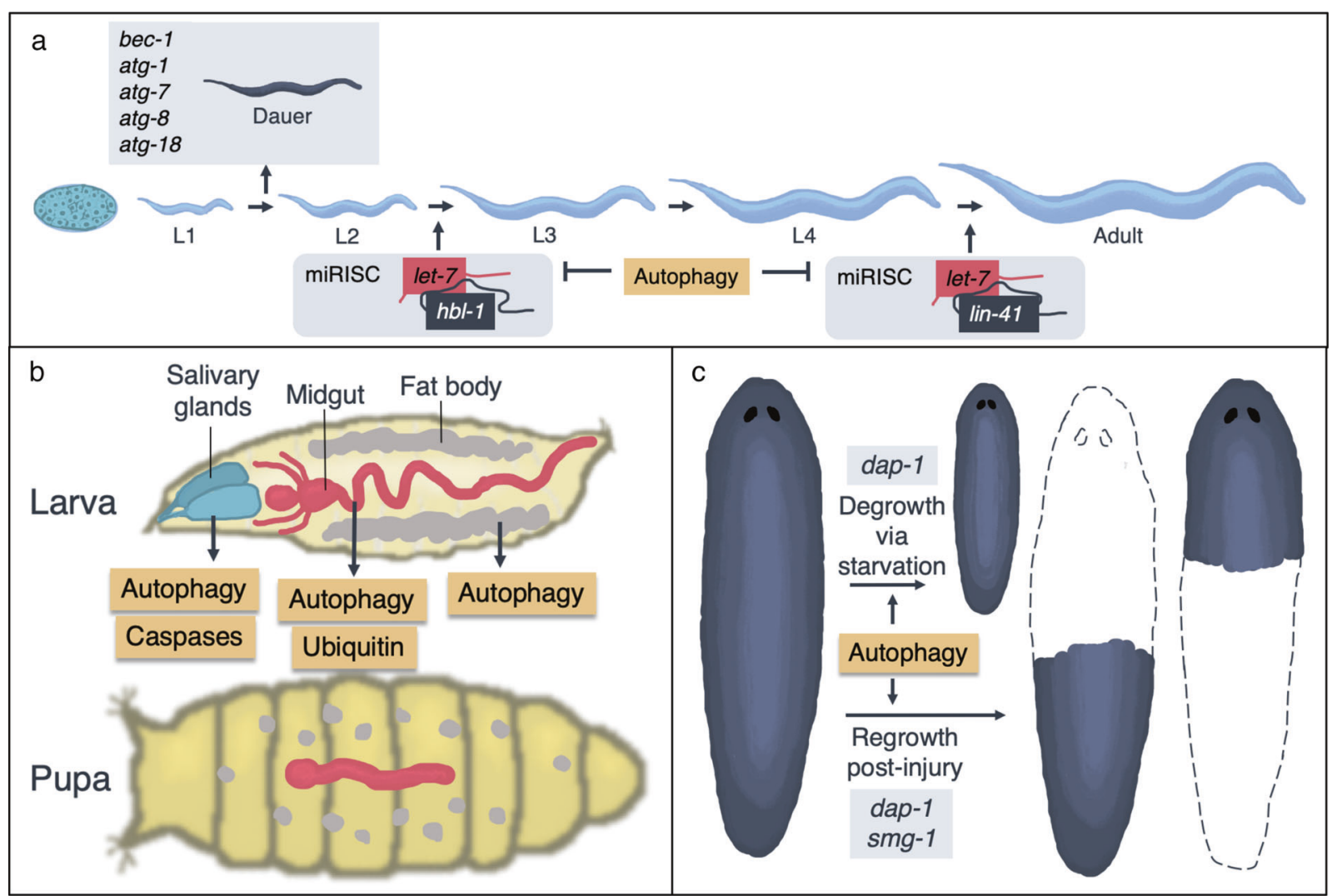

Fig. 4 Post-embryonic autophagy. a $C$. elegans require autophagic components to transition into the dauer stage, and to mediate heterochronic gene regulation by degrading components of the miRISC complex. b During Drosophila metamorphosis, autophagy is required for the breakdown of larval tissues, where in specific contexts may function with other cell death pathways. c Planaria upregulate autophagic components during both degrowth and regrowth.

glucose and amino-acid concentrations to mTORC1, and ultimately regulate autophagy in neonates. Like autophagy gene-knockout mice, constitutively active RagA (RagA ${ }^{\text {GTP }}$ ) knock-in mice fail to survive the neonatal starvation period [82]. Shortly after birth, RagA ${ }^{\text {GTP/GTP }}$ fasted neonates lack mTORC1 inhibition, fail to induce autophagy, and remain hypoglycemic until death. In fasted wild-type littermates, mTORC1 inhibition and hypoglycemia occur, and plasma amino-acid levels drop, but after prolonged fasting, plasma glucose levels recover. Presumably, the amino acids produced by autophagy during the early neonatal period are required to sustain gluconeogenesis in the liver, and constitutive RagA activity ultimately results in lethal energetic exhaustion in neonates [82]. Thus, following birth, the Rag GTPases sense the disruption of the placental nutrient supply, leading to a pro-survival autophagic program that maintains whole-animal homeostasis through the embryo to neonate transition.

\section{Autophagy in Drosophila metamorphosis}

Around the time that de Duve and Wattiaux described autophagy [5], studies in insects provided a first line of 
evidence that autophagy is associated with tissue degradation during metamorphosis, the transition from the larval to adult stages. In 1965, Schin and Clever showed that during metamorphosis in the midge, Chironomus tentans, salivary gland cells undergo lysosome-mediated degradation [83]. Locke and Collins also revealed that just prior to metamorphosis, fat body cells of the butterfly Calpodes ethlius sequester cytoplasmic contents within membranes [84]. Shortly thereafter, similar tissue regressions were reported, such as in the prothoracic glands of other insects [85] and in the salivary glands of other species [86]. In 1977, Beaulaton and Lockshin provided evidence that during Lepidoptera metamorphosis intersegmental muscles are degraded by autophagy [87]. Decades later, our group elucidated several mechanisms by which autophagy degrades the intestine and salivary glands during development to mediate nonapoptotic cell death in Drosophila melanogaster [88-91].

Animal metamorphosis requires both a continuous nutrient supply for growth and an intricate crosstalk between autophagy and apoptosis for rapid body-plan remodeling. The Drosophila life cycle includes the larval, pupal, and adult stages, each of which requires unique body morphologies to support stage-specific needs, including feeding, body pattern remodeling, and reproduction. Following embryogenesis and hatching, larvae feed continually, and rapid growth occurs across the three larval stages in about 4 days. Growth arrest occurs at the onset of pupariation, the cuticle hardens and larval tissues are removed while adult tissues develop over $\sim 4$ days.

In Drosophila, autophagy is associated with multiple larval tissues during metamorphosis (Fig. 4b). Autophagy is induced in the Drosophila fat body just prior to pupariation [92]. At the onset of pupariation, the Drosophila larval intestine undergoes rapid cell size reduction and caspase-independent cell death by autophagy, and at $10-12 \mathrm{~h}$ after pupariation the salivary glands begin to undergo cell death that depends upon both caspases and autophagy. These developmental programs occur in response to the metamorphosis-inducing steroid hormone 20-hydroxyecdysone (ecdysone), which increases temporally, first at the end of the larval period and again at 10-12 $\mathrm{h}$ after puparium formation. Ecdysone promotes a transcriptional program that includes upregulation of autophagy genes [93], and flies with mutations in genes that promote ecdysone signaling have reduced levels of autophagy genes and fail to form autophagic stuctures [88, 89, 94].

An important regulator of cell growth, the conserved class I phosphoinositide 3-kinase (PI3KC1) pathway signals through p110 and Akt to activate TOR in nutrient-rich conditions, which inhibits autophagy via the Atg1/ULK complex [95] and promotes protein synthesis. In the Drosophila fat body, PI3KC1 signaling suppresses autophagy throughout larval development until the last larval stage when ecdysone signaling inhibits $\mathrm{PI} 3 \mathrm{KCl}$ signaling and activates autophagy [92]. Indeed, dominant-negative ecdysone receptor expression in fat body reduces autophagy in late larval fat body, and the ecdysone analog RH5849 stimulates autophagy in early third larval stage fat body [92].

Autophagy during salivary gland cell death requires cell growth arrest. Expression of the PI3KC1 activity-reporter tGPH inversely correlates with the autophagy reporter GFPLC3. Indeed, salivary glands in feeding larvae express high levels of cortical tGPH and contain very few GFP-LC3 spots while $6 \mathrm{~h}$ after puparium formation glands lose cortical tGPH, and by $13.5 \mathrm{~h}$ APH glands contain numerous GFPLC3 spots [91]. Misexpression of PI3KC1 positive-regulators, such as Dp110 (the PI3K active subunit), Akt, and activated Ras ${ }^{\mathrm{V} 12}$, produces overgrown salivary glands and prevents gland autophagic degradation in a TOR-dependent manner [91]. Autophagic salivary gland clearance also fails in the absence of the proton-coupled pyruvate transporter hermes, which is a SLC16A11 ortholog that mediates TOR signaling [96]. In salivary gland cells without hermes, increased TOR activity suppresses autophagy, which impairs cell clearance, but reduced TOR function in hermes-deficient cells promotes gland clearance [96].

Drosophila salivary gland cell death requires miRNAmediated post-transcriptional gene regulation. In salivary glands that are undergoing developmental cell death, the miRNA mir-14 is both necessary and sufficient for autophagy, but not caspase activity or hormone signaling, and mir-14 misexpression can induce premature autophagy in salivary glands [97]. Mechanistically, mir-14 targets inositol 1,4,5-triphosphate kinase 2 ( $i p 3 k 2$ ), and $i p 3 k 2$ mediates inositol 1,4,5-triphosphate (IP3) signaling via endoplasmic reticulum calcium release. Furthermore, salivary gland cell death by autophagy requires both the calcium-binding protein Calmodulin and IP3 signaling. Interestingly, no role exists for either mir-14 or IP3-mediated Calmodulin signaling in starvation-induced autophagy in the Drosophila fat body [97].

Larval salivary gland clearance requires both autophagy and caspases [91, 98]. Unlike other developmental contexts in which dying cells are engulfed by phagocytic cells, salivary gland degradation does not require Drosophila phagocytes [98, 99]. However, autophagy in Drosophila salivary gland cells is regulated non-autonomously. Drosophila macroglobulin complement-related (Mcr), a complement ortholog signals through the immune receptor Draper in neighboring cells to regulate autophagy but not caspase activity during developmental salivary gland cell death [99]. A similar Mcr-Draper signaling axis-induced autophagy exists in the macrophage in response to wound healing. Src42A phosphorylates Draper and is required for salivary gland clearance [100], and in the absence of Mcr, constitutively active Src42A expression is sufficient to 
promote gland clearance [99]. However, neither Draper nor Mcr facilitates starvation-induced autophagy in the fat body.

Drosophila larval midgut degradation occurs early in metamorphosis. Within $4 \mathrm{~h}$ after the onset of pupariation, midgut cells undergo cell size reduction, and despite activation of both caspases and autophagy, only autophagy is essential for midgut cell size reduction that is associated with cell death. Indeed, caspase-inhibition permits and autophagy-inhibition delays midgut removal [101]. Both developmentally programmed cell size reduction and autophagic vesicle formation in midgut cells require the canonical autophagy components Atg1, Atg2, Atg5, Atg6, Atg8a, Atg12, Atg13, Atg16, Atg18, and Vps34. However, midgut developmental cell death by autophagy, which includes mitochondrial clearance, occurs independent of Atg7 and Atg3 and instead requires the E1 enzyme Uba1 [102]. Cells that possess defective Ubal fail to shrink and show reduced autophagic puncta compared with controls [102]. However, despite Atg8a puncta formation, Uba1 activates ubiquitin but fails to activate Atg8a [102]. Remarkably, both Atg8a puncta formation and cell size reduction require ubiquitin, but apparently not Atg8alipidation [102]. In addition, the ubiquitin binding domain-encoding Vps13D protein is required for midgut cell autophagy, size reduction, and clearance of mitochondria [103]. Thus, midgut autophagy during Drosophila metamorphosis represents a unique context in which both canonical and non-canonical autophagy molecules participate with ubiquitin for rapid cargo clearance and cell size reduction.

\section{Autophagy in regeneration}

Stem cells are critical to the health of adult animals by enabling the regeneration of organs and tissues following stress and damage. Autophagy functions in stem cells of diverse taxa and regulates cellular and organismal homeostasis to influence health and life span.

\section{Planarian autophagy}

Planaria are flatworms with the remarkable abilities to withstand long starvation periods and regenerate. These small worms provide a unique in vivo experimental system in which adult animals undergo both cell deletion and tissue reduction in response to nutrient restriction or injury, and cells undergo constant turnover throughout the life span of the animal [104]. Planarian tissues possess massive numbers of adult stem cells (neoblasts), which can self-renew, proliferate, and migrate to injury sites, and almost any small piece of planarian body can produce a full organism in $\sim 10$ days. Meanwhile, animals degrow or shrink when food is restricted, and with restored food availability, cell number increases until the animal reaches its original size. Interestingly, both starvation and regeneration feature characteristics of programmed cell death and autophagy [105108] (Fig. 4c), and like in higher organisms, planarians possess a TOR-mediated autophagy signaling pathway [109, 110].

Starved planarians undergo spatiotemporal body size reduction with a total loss of $\sim 30 \%$ body size after five weeks [106]. During degrowth, cell size and neoblast mitotic rate remain unaffected while cell numbers decrease [111, 112]. Autophagic vesicles appear at several time points in starved planarians [106]. Meanwhile, we know very little about the molecular regulation of degrowth. Starved animals increase expression levels of dap-1, the ortholog of the human death-associated protein-1 (DAP-1) [113], but dap- 1 regulation is better understood in planarian wound regeneration. Regenerating wound sites increase dap- 1 expression, specifically within a population of cells undergoing autophagy, while apoptotic cells lack dap-1 expression [113]. Downregulating dap-1 impairs proliferation and remodeling [113]. However, gain-of-function mutant dap- 1 animals fail to mature, and mosaic animals repeatedly undergo cycles of cell death and regeneration in tissues that possess dap-1 gain-of-function cells [113].

Planarian regeneration requires both new tissue production and old tissue remodeling. Early observations of fine structures via transmission electron microscopy indicate that wounded cells are phagocytosed by healthy neighboring cells and wound-adjacent parenchymal cells contain autophagic vesicles [107]. Nevertheless, more recent studies reveal the molecular regulation of planarian wound healing and regeneration. Indeed, genes that regulate both apoptosis and autophagy are differentially regulated in regenerative tissues [114]. At wound sites, neoblasts migrate and form an unpigmented regenerative compartment called the blastema. The blastema progressively undergoes pigmentation, and neoblasts terminally differentiate to form missing body tissues. In tor- and raptor-knockdown animals, differentiation and regeneration occur in the absence of blastema formation [109]. In addition, smg-1 is the planarian homolog of the human PI3K-related kinase (PIKK) family member SMG-1 [109]. In injured smg-1 knockdown animals, neoblasts form a blastema but hyper-proliferate and form lethal hypertrophic growths [109]. However, reduced TOR activity suppresses over-proliferation and increases survival in smg-1 knockdown animals [109]. Interestingly, despite high expression of Atg-7 at injury sites in wild-type animals, autophagy appears to be Atg7-independent because autophagic vesicles form in Atg-7 knockdown animals at multiple sites of injury, and regeneration remains intact. Future studies should investigate if, as in 
Drosophila developmental midgut autophagy, planarian Uba-1 and Vps13D orthologs promote autophagy during regeneration.

\section{Autophagy in zebrafish regeneration}

Autophagy also mediates tissue regeneration in zebrafish (Danio rerio) at the both the amputated caudal fin and in the extraocular muscle. The amputated zebrafish caudal fin remains a relevant paradigm to investigate mechanisms underlying appendage regeneration. Like planaria wound sites, caudal fin amputation induces blastema formation at the epidermal-injury site [115]. This proliferative tissue contains undifferentiated cells that promote rapid regrowth of the fin such that a near-perfect fin exists 20 days after injury. The first sign of repair is visible 3 days after injury as a pigment-free blastemal outgrowth. By day 6 , unpigmented outgrowth continues rapidly at the distal-most region of the fin while the proximal region initiates redifferentiation with the formation of bone structures and pigmentation.

Initial stages of caudal fin regrowth coincide with autophagy activation. Proximal to the caudal fin amputation site, autophagic activity increases 2 days after injury and subsequently decreases by day 4 [116]. Compared with uninjured controls, GFP-LC3 expression in amputated transgenic zebrafish increases at day 2 and decreases by day 4 , and transmission electron micrographs of injury sites feature numerous autophagic vesicles [116]. Indeed, autophagy is required for caudal fin regeneration because both genetic and pharmacological inhibition of autophagy impairs regrowth, as respectively demonstrated by Atg5 silencing and bafilomycin A1 treatments [116]. Furthermore, impaired autophagy decreases proliferation and increases apoptotic activity at 3-day-old wound sites and impairs blastema cell differentiation at multiple time points after injury [116]. Regeneration also depends on activity of Mapk/Erk, a growth factor signaling cascade and known autophagy stimulator, and autophagy at regenerating wound sites is Mapk/Erk-dependent. In injured fins treated with the pharmacological Mapk/Erk inhibitor U0126, autophagic vesicle numbers at wound sites decrease compared with vehicle-treated controls [116]. These data suggest that autophagy plays a critical and early role in regeneration.

Unlike the caudal fin, the adult zebrafish extraocular muscle first undergoes cellular reprogramming prior to regeneration [117]. After injury, residual myocytes dedifferentiate into myoblasts, which then proliferate and redifferentiate into functional muscle fibers [117]. Reprogramming occurs within $18 \mathrm{~h}$ post injury [117] and autophagy promotes regeneration during this time-frame [118]. At $16 \mathrm{~h}$ post injury wound sites, increased GFP-LC3 is detectable by fluorescence microscopy, LC3-II protein levels increase, and autophagic vesicles are visible in transmission electron micrographs, while uninjured control extraocular muscle lacks these features [118]. Similar to the caudal fin model, genetic and pharmacological inhibition of autophagy impairs regeneration, and growth factor signaling is required for autophagy [118]. Interestingly, autophagy promotes sarcomere organization during regeneration because at 5 days post injury, transmission electron micrographs of regenerating muscle from animals subjected to autophagy inhibiton feature improperly organized sacromeres compared with untreated animals [118]. Further, DNA accumulates in autophagy-inhibited regenerating muscle but not in control vehicle-treated controls, which suggests that autophagy promotes degradation of nuclei from multinucleated myocytes [118]. These data suggest that dedifferentiation of myocytes into myoblasts prior to regeneration requires autophagy-mediated cytoplasmic remodeling.

\section{Autophagy in regeneration of the Drosophila intestine}

The Drosophila intestine undergoes age related changes that are similar to the mammalian intestine, including increased stem cell proliferation, mis-differentiation of cells, and permeability of the intestinal epithelial barrier resulting in death [119-121]. Autophagy is required for adult Drosophila intestine stem cell and organism health. Decreased function of multiple Atg genes, including Atg2, Atg3, Atg6, Atg8a, Atg14, and Atg18, results in stem cell loss and decreased life span [122]. By contrast, altered function of autophagy genes, including Atg1, Atg5, Atg6, Atg7, Atg8a, Atg9, Atg12, and Atg16, caused an increase in stem cell numbers and over-growth associated with the activation of EGFR and ERK signaling [123]. In addition, Atg9 acts in an autophagy-independent manner to promote JNK induced intestine stem cell proliferation following oxidative stress [124]. These studies may highlight distinct functions of different autophagy genes in stem cells. Alternatively, it is possible that differences in the age of animals when Atg gene function is altered is responsible for these distinct stem cell phenotypes. Additional research is required to fully understand how autophagy contributes to intestine stem cells and health.

\section{Conclusions and outlook}

We owe our current understanding of the mechanisms that regulate autophagy to research that spans the last quarter of a century. As a result of experiments that focus on developmental biology, we gained knowledge about mechanisms that underlie autophagy in different cell contexts that are relevant to disease. For example, experiments using $C$. elegans to investigate sperm mitophagy could clarify if 
heteroplasmy contributes to mitochondrial disease or if mitophagy could be utilized in human assisted reproductive therapy [27]. Furthermore, protein aggregate-clearance failure is a hallmark of neurodegenerative disease, and studies of how cells clear aggregates during development could explain defects that promote disease. Defects in apoptotic cell clearance contribute to inflammation and autoimmunity [125]. Therefore, the relationship between Drosophila Mcr and Draper in autophagy may reveal conserved roles for C1q and Megf10 in mammalian autophagy. Lastly, we know little about autophagic regulation of miRNAs in cancer progression and much more about the opposite, how miRNAs regulate autophagy [77]. Thus, studying how miRNAs are dysregulated in autophagydeficient model organisms during development could provide novel mechanisms that regulate cancer biology. Importantly, work on context-specific regulatory mechanisms is critical to understanding how to best treat cell- and organ- specific diseases. Thus, future work on developmentally programmed autophagy has great potential to advance our understanding of autophagy in both normal and disease settings.

\section{Compliance with ethical standards}

Conflict of interest The authors declare that they have no conflict of interest.

Publisher's note Springer Nature remains neutral with regard to jurisdictional claims in published maps and institutional affiliations.

\section{References}

1. de Duve C, Pressman BC, Gianetto R, Wattiaux R, Appelmans F. Tissue fractionation studies: Intracellular distribution patterns of enzymes in rat-liver tissue. Biochem J. 1955;60:604-17.

2. Settembre C, Fraldi A, Medina DL, Ballabio A. Signals from the lysosome: a control centre for cellular clearance and energy metabolism. Nat Rev Mol Cell Biol. 2013;14:283-96.

3. Mony VK, Benjamin S, O'Rourke EJ. A lysosome-centered view of nutrient homeostasis. Autophagy. 2016;12:619-31.

4. Lawrence RE, Zoncu R. The lysosome as a cellular centre for signalling, metabolism and quality control. Nat Cell Biol. 2019;21:133-42.

5. de Duve C, Wattiaux R. Functions of lysosomes. Annu Rev Physiol. 1966;28:435-92.

6. Santambrogio L, Cuervo AM. Chasing the elusive mammalian microautophagy. Autophagy. 2011. https://doi.org/10.4161/auto. 7.6.15287.

7. Chiang HL, Terlecky SR, Plant CP, Dice JF. A role for a 70kilodaton heat shock protein in lysosomal degradation of intracellular proteins. Science. 1989;246:382-5.

8. Cuervo AM, Dice JF. A receptor for the selective uptake and degradation of proteins by lysosomes. Science. 1996;273:501-3.

9. Salvador N, Aguado C, Horst M, Knecht E. Import of a cytosolic protein into lysosomes by chaperone-mediated autophagy depends on its folding state. J Biol Chem. 2000;275:27447-56.
10. Agarraberes FA, Terlecky SR, Dice JF. An intralysosomal hsp70 is required for a selective pathway of lysosomal protein degradation. J Cell Biol. 1997;137:825-34.

11. Ashford TP, Porter KR. Cytoplasmic components in hepatic cell lysosomes. J Cell Biol. 1962;12:198-202.

12. Arstila AU, Trump BF. Studies on cellular autophagocytosis. The formation of autophagic vacuoles in the liver after glucagon administration. Am J Pathol. 1968;53:687-733.

13. Takeshige K, Baba M, Tsuboi S, Noda T, Ohsumi Y. Autophagy in yeast demonstrated with proteinase-deficient mutants and conditions for its induction. J Cell Biol. 1992;119:301-11.

14. Thumm M, Egner R, Koch B, Schlumpberger M, Straub M, Veenhuis $\mathrm{M}$, et al. Isolation of autophagocytosis mutants of Saccharomyces cerevisiae. FEBS Lett. 1994;349:275-80.

15. Tsukada M, Ohsumi Y. Isolation and characterization of autophagy-defective mutants of Saccharomyces cerevisiae. FEBS Lett. 1993;333:169-74.

16. Ohsumi Y. Molecular dissection of autophagy: two ubiquitinlike systems. Nat Rev Mol Cell Biol. 2001;2:211-6.

17. Yang Z, Klionsky DJ. Mammalian autophagy: Core molecular machinery and signaling regulation. Curr Opin Cell Biol. 2010; 22:124-31.

18. Levine B, Klionsky DJ. Development by self-digestion: molecular mechanisms and biological functions of autophagy. Dev Cell. 2004;6:463-77.

19. Mercer TJ, Gubas A, Tooze SA. A molecular perspective of mammalian autophagosome biogenesis. J Biol Chem. 2018;293: 5386-95.

20. Ganley IG, Lam DH, Wang J, Ding X, Chen S, Jiang X. ULK1-ATG13·FIP200 complex mediates mTOR signaling and is essential for autophagy. J Biol Chem. 2009;284:12297-305.

21. Nakatogawa H. Two ubiquitin-like conjugation systems that mediate membrane formation during autophagy. Essays Biochem. 2013;55:39-50.

22. Itakura E, Mizushima N. Characterization of autophagosome formation site by a hierarchical analysis of mammalian Atg proteins. Autophagy. 2010;6:764-76.

23. Saxton RA, Sabatini DM. mTOR signaling in growth, metabolism, and disease. Cell. 2017;168:960-76.

24. Reggiori F, Ungermann C. Autophagosome maturation and fusion. J Mol Biol. 2017;429:486-96.

25. Rong Y, McPhee CK, McPhee C, Deng S, Huang L, Chen L, et al. Spinster is required for autophagic lysosome reformation and mTOR reactivation following starvation. Proc Natl Acad Sci USA. 2011;108:7826-31.

26. Yu L, Chen Y, Tooze SA. Autophagy pathway: cellular and molecular mechanisms. Autophagy. 2018;14:207-15.

27. Song WH, Yi YJ, Sutovsky M, Meyers S, Sutovsky P. The ART and science of sperm mitophagy. Autophagy. 2016;12:2510-1.

28. Sato M, Sato K. Degradation of paternal mitochondria by fertilization-triggered autophagy in C. elegans embryos. Science. 2011;334:1141-4.

29. Al Rawi S, Louvet-Vallée S, Djeddi A, Sachse M, Culetto E, Hajjar C, et al. Postfertilization autophagy of sperm organelles prevents paternal mitochondrial DNA transmission. Science. 2011;334:1144-7.

30. Shakes DC, Ward S. Mutations that disrupt the morphogenesis and localization of a sperm-specific organelle in Caenorhabditis elegans. Dev Biol. 1989;231:1-23.

31. Wei Y, Chiang WC, Sumpter R, Mishra P, Levine B. Prohibitin 2 is an inner mitochondrial membrane mitophagy receptor. Cell. 2017;168:224-38.

32. Hird SN, Paulsen JE, Strome S. Segregation of germ granules in living Caenorhabditis elegans embryos: cell-type-specific mechanisms for cytoplasmic localisation. Development. 1996; 122:1303-12. 
33. Zhang Y, Yan L, Zhou Z, Yang P, Tian E, Zhang K, et al. SEPA1 mediates the specific recognition and degradation of $p$ granule components by autophagy in C. elegans. Cell. 2009;136:308-21.

34. Komatsu M, Waguri S, Koike M, Sou Y-S, Ueno T, Hara T, et al. Homeostatic levels of p62 control cytoplasmic inclusion body formation in autophagy-deficient mice. Cell. 2007;131: 1149-63.

35. Nezis IP, Simonsen A, Sagona AP, Finley K, Gaumer S, Contamine D, et al. $\operatorname{Ref}(2) \mathrm{P}$, the drosophila melanogaster homologue of mammalian p62, is required for the formation of protein aggregates in adult brain. J Cell Biol. 2008;180:1065-71.

36. Tian Y, Li Z, Hu W, Ren H, Tian E, Zhao Y, et al. C. elegans screen identifies autophagy genes specific to multicellular organisms. Cell. 2010;141:1042-55.

37. Zhang G, Wang Z, Du Z, Zhang H. mTOR regulates phase separation of PGL granules to modulate their autophagic degradation. Cell. 2018;174:1492-.e22.

38. Tsukamoto S, Kuma A, Murakami M, Kishi C, Yamamoto A, Mizushima N. Autophagy is essential for preimplantation development of mouse embryos. Science. 2008;321:117-20.

39. Merz EA, Brinster RL, Brunner S, Chen HY. Degradation during preimplantation development. J Reprod Fert. 1981; 61:451-418.

40. Kuma A, Hatano M, Matsui M, Yamamoto A, Nakaya H, Yoshimori $\mathrm{T}$, et al. The role of autophagy during the early neonatal starvation period. Nature. 2004;432:1032-6.

41. Komatsu M, Waguri S, Ueno T, Iwata J, Murata S, Tanida I, et al. Impairment of starvation-induced and constitutive autophagy in Atg7-deficient mice. J Cell Biol. 2005;169:425-34.

42. Yamamoto A, Mizushima N, Tsukamoto S. Fertilization-induced autophagy in mouse embryos is independent of mTORC1. Biol Reprod. 2014;91:1-7.

43. Cheong H, Lindsten T, Wu J, Lu C, Thompson CB. Ammoniainduced autophagy is independent of ULK1/ULK2 kinases. Proc Natl Acad Sci USA. 2011;108:11121-6.

44. Feng Y, Kang HH, Wong PM, Gao M, Wang P, Jiang X. Unc51-like kinase (ULK) complex-independent autophagy induced by hypoxia. Protein Cell. 2019;10:376-81.

45. Corona Velazquez A, Corona AK, Klein KA, Jackson WT. Poliovirus induces autophagic signaling independent of the ULK1 complex. Autophagy. 2018;14:1201-13.

46. Yue Z, Jin S, Yang C, Levine AJ, Heintz N. Beclin 1, an autophagy gene essential for early embryonic development, is a haploinsufficient tumor suppressor. Proc Natl Acad Sci USA. 2003;100:15077-82.

47. Maria Fimia G, Stoykova A, Romagnoli A, Giunta L, Di Bartolomeo S, Nardacci R, et al. Ambral regulates autophagy and development of the nervous system. Nature. 2007;447:1121-5.

48. Yazdankhah M, Farioli-Vecchioli S, Tonchev AB, Stoykova A, Cecconi F. The autophagy regulators Ambra1 and Beclin 1 are required for adult neurogenesis in the brain subventricular zone. Cell Death Dis. 2014;5:e1403.

49. Cianfanelli V, De Zio D, Di Bartolomeo S, Nazio F, Strappazzon F, Cecconi F. Ambra1 at a glance. J Cell Sci. 2015;128:2003-8.

50. Grimsley C, Ravichandran KS. Cues for apoptotic cell engulfment: eat-me, don't eat-me and come-get-me signals. Trends Cell Biol. 2003;13:648-56.

51. Conradt B, Wu YC, Xue D. Programmed cell death during Caenorhabditis elegans development. Genetics. 2016;203:1533-62.

52. Huang S, Jia K, Wang Y, Zhou Z, Levine B. Autophagy genes function in apoptotic cell corpse clearance during C. Elegans embryonic development. Autophagy. 2013;9:1-12.

53. Cheng S, Wu Y, Lu Q, Yan J, Zhang H, Wang X. Autophagy genes coordinate with the class II PI/PtdIns 3-kinase PIKI-1 to regulate apoptotic cell clearance in C. elegans. Autophagy. 2013;9:2022-32.
54. Jenzer C, Simionato E, Largeau C, Scarcelli V, Lefebvre C, Legouis R. Autophagy mediates phosphatidylserine exposure and phagosome degradation during apoptosis through specific functions of GABARAP/LGG-1 and LC3/LGG-2. Autophagy. $2019 ; 15: 228-41$.

55. Li W, Zou W, Yang Y, Chai Y, Chen B, Cheng S, et al. Autophagy genes function sequentially to promote apoptotic cell corpse degradation in the engulfing cell. J Cell Biol. 2012; 197:27-35.

56. Ruck A, Attonito J, Garces KT, Núnez L, Palmisano NJ, Rubel $\mathrm{Z}$, et al. The $\operatorname{Atg} 6 / \mathrm{Vps} 30 / \mathrm{Beclin} 1$ ortholog BEC-1 mediates endocytic retrograde transport in addition to autophagy in $\mathrm{C}$. elegans. Autophagy. 2011;7:386-400.

57. Takacs-Vellai K, Vellai T, Puoti A, Passannante M, Wicky C, Streit A, et al. Inactivation of the autophagy Gene bec-1 triggers apoptotic cell death in C. elegans. Curr Biol. 2005;15:1513-7.

58. Reed BH, Wilk R, Schöck F, Lipshitz HD. Integrin-dependent apposition of Drosophila extraembryonic membranes promotes morphogenesis and prevents anoikis. Curr Biol. 2004;14: 372-80.

59. Mohseni N, McMillan SC, Chaudhary R, Mok J, Reed BH. Autophagy promotes caspase-dependent cell death during Drosophila development. Autophagy. 2009;5:329-38.

60. Cormier O, Mohseni N, Voytyuk I, Reed BH. Autophagy can promote but is not required for epithelial cell extrusion in the amnioserosa of the Drosophila embryo. Autophagy. 2012;8: 252-64.

61. Coucouvanis E, Martin GR. Signals for death and survival: a two-step mechanism for cavitation in the vertebrate embryo. Cell 1995;83. https://doi.org/10.1016/0092-8674(95)90169-8.

62. Qu X, Zou Z, Sun Q, Luby-Phelps K, Cheng P, Hogan RN, et al. Autophagy gene-dependent clearance of apoptotic cells during embryonic development. Cell. 2007;128:931-46.

63. Mellén MA, de la Rosa EJ, Boya P. The autophagic machinery is necessary for removal of cell corpses from the developing retinal neuroepithelium. Cell Death Differ. 2008;15:1279-90.

64. Mellén MA, De La Rosa EJ, Boya P. Autophagy is not universally required for phosphatidyl-serine exposure and apoptotic cell engulfment during neural development. Autophagy. 2009; 5:964-72.

65. Meléndez A, Tallóczy Z, Seaman M, Eskelinen EL, Hall DH, Levine B. Autophagy genes are essential for dauer development and life-span extension in C. elegans. Science. 2003;301:1387-91.

66. Carthew RW, Sontheimer EJ. Origins and Mechanisms of miRNAs and siRNAs. Cell. 2009;136:642-55.

67. Ding L, Han M. GW182 family proteins are crucial for microRNA-mediated gene silencing. Trends Cell Biol. 2007; 17:411-6.

68. Ambros V. MicroRNAs and developmental timing. Curr Opin Genet Dev. 2011;21:511-7.

69. Lehmann R, Nüsslein-Volhard C. hunchback, a gene required for segmentation of an anterior and posterior region of the Drosophila embryo. Dev Biol. 1987;119:402-17.

70. Struhl G, Johnston P, Lawrence PA. Control of Drosophila body pattern by the hunchback morphogen gradient. Cell. 1992; 69:237-49.

71. Fay DS, Stanley HM, Han M, Wood WB. A Caenorhabditis elegans homologue of hunchback is required for late stages of development but not early embryonic patterning. Dev Biol. 1999;205:240-53.

72. Abbott AL, Alvarez-Saavedra E, Miska EA, Lau NC, Bartel DP, Horvitz HR, et al. The let-7 MicroRNA family members mir-48, mir-84, and mir-241 function together to regulate developmental timing in Caenorhabditis elegans. Dev Cell. 2005;9:403-14.

73. Ding L, Spencer A, Morita K, Han M. The developmental timing regulator AIN-1 interacts with miRISCs and may target the 
argonaute protein ALG-1 to cytoplasmic P bodies in C. elegans. Mol Cell. 2005;19:437-47.

74. Zhang L, Ding L, Cheung TH, Dong MQ, Chen J, Sewell AK, et al. Systematic identification of C. elegans miRISC proteins, miRNAs, and mRNA targets by their Interactions with GW182 proteins AIN-1 and AIN-2. Mol Cell. 2007;28:598-613.

75. Zhang P, Zhang H. Autophagy modulates miRNA-mediated gene silencing and selectively degrades AIN-1/GW182 in C. elegans. EMBO Rep. 2013;14:568-76.

76. Gibbings D, Mostowy S, Jay F, Schwab Y, Cossart P, Voinnet O. Selective autophagy degrades DICER and AGO2 and regulates miRNA activity. Nat Cell Biol. 2012;14:1314-21.

77. Gozuacik D, Akkoc Y, Gulfem Ozturk D, Kocak M. Autophagyregulating microRNAs and cancer. Front Oncol. 2017;7:1-22.

78. Petri R, Pircs K, Jönsson ME, Åkerblom M, Brattås PL, Klussendorf $\mathrm{T}$, et al. let-7 regulates radial migration of new-born neurons through positive regulation of autophagy. EMBO J. 2017;36:1379-91.

79. Sou YS, Waguri S, Iwata JI, Ueno T, Fujimura T, Hara T, et al. The Atg8 conjugation system is indispensable for proper development of autophagic isolation membranes in mice. Mol Biol Cell. 2008;19:4762-75.

80. Saitoh T, Fujita N, Hayashi T, Takahara K, Satoh T, Lee H, et al. Atg9a controls dsDNA-driven dynamic translocation of STING and the innate immune response. Proc Natl Acad Sci USA. 2009;106:20842-6.

81. Saitoh T, Fujita N, Jang MH, Uematsu S, Yang BG, Satoh T, et al. Loss of the autophagy protein Atg16L1 enhances endotoxin-induced IL-1 $\beta$ production. Nature. 2008;456:264-8.

82. Efeyan A, Zoncu R, Chang S, Gumper I, Snitkin H, Wolfson RL, et al. Regulation of mTORC1 by the Rag GTPases is necessary for neonatal autophagy and survival. Nature. 2012;493:679.

83. Schin KS, Clever U. Lysosomal and free acid phosphatase in salivary glands of chironomus tentans. Science. 1965;150: 1053-5.

84. Locke M, Collins JV. The structure and formation of protein granules in the fat body of an insect. J Cell Biol. 1965; 26:857-84.

85. Scharrer B. Ultrastructural study of the regressing prothoracic glands of blattarian insects. Z für Zellforsch und Mikroskopische Anat. 1966;69:1-21.

86. Schin K, Laufer H. Studies of programmed salivary gland regression during larval-pupal transformation in Chironomus thummi. Exp Cell Res. 1973;82:335-40.

87. Beaulaton J, Lockshin RA. Ultrastructural study of the normal degeneration of the intersegmental muscles of Antheraea polyphemus and Manduca sexta (Insecta, lepidoptera) with particular reference to cellular autophagy. J Morphol. 1977; 154:39-57.

88. Lee CY, Baehrecke EH. Steroid regulation of autophagic programmed cell death during development. Development. 2001; 128:1443-55.

89. Baehrecke EH. Autophagic programmed cell death in Drosophila. Cell Death Differ. 2003;10:940-5.

90. Denton D, Shravage B, Simin R, Mills K, Berry DL, Baehrecke $\mathrm{EH}$, et al. Autophagy, not apoptosis, is essential for midgut cell death in drosophila. Curr Biol. 2009;19:1741-6.

91. Berry DL, Baehrecke EH. Growth arrest and autophagy are required for salivary gland cell degradation in drosophila. Cell. 2007;131:1137-48.

92. Rusten TE, Lindmo K, Juhász G, Sass M, Seglen PO, Brech A, et al. Programmed autophagy in the Drosophila fat body is induced by ecdysone through regulation of the PI3K Pathway. Dev Cell. 2004;7:179-92.

93. Lee CY, Clough EA, Yellon P, Teslovich TM, Stephan DA, Baehrecke EH. Genome-wide analyses of steroid- and radiation- triggered programmed cell death in Drosophila. Curr Biol. 2003;13:350-7.

94. Lee C-Y, Cooksey BAK, Baehrecke EH. Steroid regulation of midgut cell death during drosophila development. Dev Biol. 2002;250:101-11.

95. Kamada Y, Funakoshi T, Shintani T, Nagano K, Ohsumi M, Ohsumi Y. Tor-mediated induction of autophagy via an Apg1 protein kinase complex. J Cell Biol. 2000;150:1507-13.

96. Velentzas PD, Zhang L, Das G, Chang TK, Nelson C, Kobertz $\mathrm{WR}$, et al. The proton-coupled monocarboxylate transporter hermes is necessary for autophagy during cell death. Dev Cell. 2018;47:281-93.

97. Nelson C, Ambros V, Baehrecke EH. miR-14 regulates autophagy during developmental cell death by targeting ip3-kinase 2 . Mol Cell. 2014;56:376-88.

98. Martin DN, Baehrecke EH. Caspases function in autophagic programmed cell death in Drosophila. Development. 2004; 131:275-84.

99. Lin L, Rodrigues FSLM, Kary C, Contet A, Logan M, Baxter RHG, et al. Complement-related regulates autophagy in neighboring cells. Cell. 2017;170:158-.e8.

100. McPhee CK, Logan MA, Freeman MR, Baehrecke EH. Activation of autophagy during cell death requires the engulfment receptor Draper. Nature. 2010;465:1093-7.

101. Denton D, Shravage B, Simin R, Mills K, Berry DL, Baehrecke $\mathrm{EH}$, et al. Autophagy, not apoptosis, is essential for midgut cell death in drosophila. Curr Biol. 2009. https://doi.org/10.1016/j. cub.2009.08.042.

102. Chang T-K, Shravage BV, Hayes SD, Powers CM, Simin RT, Wade Harper $J$, et al. Uba1 functions in Atg7- and Atg3independent autophagy. Nat Cell Biol. 2013;15:1067-78.

103. Anding AL, Wang C, Chang TK, Sliter DA, Powers CM, Hofmann $\mathrm{K}$, et al. Vps13D encodes a ubiquitin-binding protein that is required for the regulation of mitochondrial size and clearance. Curr Biol. 2018;28:287-95.

104. Felix DA, Gutiérrez-Gutiérrez Ó, Espada L, Thems A, GonzálezEstévez C. It is not all about regeneration: planarians striking power to stand starvation. Semin Cell Dev Biol. 2019;87: 169-81.

105. Bowen ID, Ryder TA. Cell autolysis and deletion in the planarian polycelis tenuis Iijima. Cell Tissue Res. 1974;154:265-74.

106. Bowen ID, Ryder TA, Dark C. The effects of starvation on the planarian worm Polycelis tenuis iijima. Cell Tissue Res. 1976;169:193-209.

107. Bowen ID, den Hollander JE, Lewis GHJ. Cell death and acid phosphatase activity in the regenerating planarian polycelis tenuis Iijima. Differentiation. 1982;21:160-7.

108. Tettamanti G, Salo E, Gonzalez-Estevez C, Felix D, Grimaldi A, Eguileor M. Autophagy in invertebrates: insights into development, regeneration and body remodeling. Curr Pharm Des. 2008;14:116-25.

109. González-Estévez C, Felix DA, Smith MD, Paps J, Morley SJ, James V, et al. SMG-1 and mTORC1 act antagonistically to regulate response to injury and growth in planarians. PLoS Genet. 2012;8:e1002619.

110. Kang J, Dong Z, Hao Q, Wang J, Chen G, Liu D. The regulation of rapamycin in planarian Dugesia japonica Ichikawa \& $\mathrm{T}$ Kawakatsu, 1964 regeneration according to TOR signaling pathway. Ecotoxicol Environ Saf. 2019;185:109680.

111. Baguñá J, Romero R. Quantitative analysis of cell types during growth, degrowth and regeneration in the planarians Dugesia mediterranea and Dugesia tigrina. Hydrobiologia. 1981;84:181-94.

112. González-Estévez C, Felix DA, Rodríguez-Esteban G, Aziz Aboobaker A. Decreased neoblast progeny and increased cell death during starvation-induced planarian degrowth. Int J Dev Biol. 2012;56:83-91. 
113. González-Estévez C, Felix DA, Aboobaker AA, Saló E. Gtdap-1 promotes autophagy and is required for planarian remodeling during regeneration and starvation. Proc Natl Acad Sci USA. 2007;104:13373-8.

114. Yuan J, Wang Z, Zou D, Peng Q, Peng R, Zou F. Expression profiling of planarians shed light on a dual role of programmed cell death during the regeneration. J Cell Biochem. 2018;119: 5875-84.

115. Pfefferli C, Jaźwińska A. The art of fin regeneration in zebrafish. Regeneration. 2015;2:72-83.

116. Varga M, Sass M, Papp D, Takács-Vellai K, Kobolak J, Dinnyés A, et al. Autophagy is required for zebrafish caudal fin regeneration. Cell Death Differ. 2014;21:547-56.

117. Saera-Vila A, Kasprick DS, Junttila TL, Grzegorski SJ, Louie $\mathrm{KW}$, Chiari EF, et al. Myocyte dedifferentiation drives extraocular muscle regeneration in adult zebrafish. Investig Ophthalmol Vis Sci. 2015;56:4977-93.

118. Saera-Vila A, Kish PE, Louie KW, Grzegorski SJ, Klionsky DJ, Kahana A. Autophagy regulates cytoplasmic remodeling during cell reprogramming in a zebrafish model of muscle regeneration. Autophagy. 2016;12:1864-75.
119. Rera M, Clark RI, Walker DW. Intestinal barrier dysfunction links metabolic and inflammatory markers of aging to death in Drosophila. Proc Natl Acad Sci USA. 2012;109:21528-33.

120. Biteau B, Karpac J, Supoyo S, DeGennaro M, Lehmann R, Jasper H. Lifespan extension by preserving proliferative homeostasis in Drosophila. PLoS Genet. 2010;6:e1001159.

121. Jiang H, Edgar BA. Intestinal stem cell function in Drosophila and mice. Curr Opin Genet Dev. 2012;22:354-60.

122. Nagy P, Sándor GO, Juhász G. Autophagy maintains stem cells and intestinal homeostasis in Drosophila. Sci Rep. 2018;8:4644.

123. Zhang P, Holowatyj AN, Roy T, Pronovost SM, Marchetti M, Liu $\mathrm{H}$, et al. An SH3PX1-dependent endocytosis-autophagy network restrains intestinal stem cell proliferation by counteracting EGFR-ERK signaling. Dev Cell. 2019;49:574-89.

124. Tang HW, Liao HM, Peng WH, Lin HR, Chen $\mathrm{CH}$, Chen GC. Atg9 interacts with dTRAF2/TRAF6 to regulate oxidative stressinduced JNK activation and autophagy induction. Dev Cell. 2013;27:489-503.

125. Elliott MR, Ravichandran KS. Clearance of apoptotic cells: Implications in health and disease. J Cell Biol. 2010;189: 1059-70. 